\title{
The incidence and localization of arterial Fenestrations of the human brain and their Association to brain aneurysms
}

\section{Wojciech Czyżewski}

Department of Didactics and Medical SImulation of Medical University of Lublin

\section{Zofia Hoffman ( $\nabla$ zofhof@gmail.com )}

Student Scientific Society, Medical University of Lublin

\section{Patrycja Korulczyk}

Department of Didactics and Medical SImulation of Medical University of Lublin

\section{Kamil Torres}

Department of Didactics and Medical SImulation of Medical University of Lublin

\section{Grzegorz Staśkiewicz}

I Department of Medical Radiology in Lublin, Independent Public Teaching Hospital no 4

\section{Research Article}

Keywords: fenestration, aneurysms, patients, vascular, occurrence

Posted Date: October 8th, 2021

DOl: https://doi.org/10.21203/rs.3.rs-785534/v1

License: (9) This work is licensed under a Creative Commons Attribution 4.0 International License. Read Full License 


\title{
THE INCIDENCE AND LOCALIZATION OF ARTERIAL FENESTRATIONS OF THE HUMAN BRAIN AND THEIR ASSOCIATION TO BRAIN ANEURYSMS
}

\author{
Wojciech Czyżewski ${ }^{1}$, Zofia Hoffman ${ }^{2, *}$, Patrycja Korulczyk ${ }^{1}$, Kamil Torres ${ }^{1}$, Grzegorz Staśkiewicz ${ }^{3}$ \\ ${ }^{1}$ Department od Didactics and Medical Simulation of Medical University of Lublin \\ ${ }^{2}$ Student Scientific Society, Medical University of Lublin \\ ${ }^{3}$ I Department of Medical Radiology in Lublin
}

*corresponding author: zofhof@gmail.com

\begin{abstract}
The aim of the study was to determine the frequency of occurrence and the most common locations of the fenestration of the cerebral arteries, i.e. developmental anomalies consisting of segmental vessel splitting and also the correlation between their presence and the formation of intracranial aneurysms.

6,545 patients in Independent Public Teaching Hospital No. 4 in Lublin in years 20092019 who have undergone the angio-CT examination of the head were retrospectively analyzed. The incidence of vascular fenestration was $0.75 \%$, of which $75 \%$ were women and $25 \%$ men. Reported vascular anomalies most often occurred in the anterior parts of the circle of Willis - ACA (30.61\%), AComA (22.45\%) and also in BA (30.61\%). It has been shown that the occurrence of different types of fenestrations was similar in the group of men and women. There have been diagnosed 11 cases of intracranial aneurysms among patients with observed fenestration (22.45\%). For comparison, the incidence of cerebral aneurysms in Western Europe and the US ranges from $2 \%$ to $6 \%$. It leads to the conclusion that among patients with fenestration, this type of vascular anomaly occurs much more often, hence they require more frequent control.
\end{abstract}

\section{INTRODUCTION}

Cerebral vascular system was firstly illustrated by English scientist and architect Christopher Wren in most notable piece of work of Thomas Willis - „Cerebri anatome” 
published in 1664 (Feindel W., 2003). Despite the fact that first cases of an incomplete circle were described relatively early, first reference to its variations did not occur until the twentieth century (A. Meyer, 1962).

The circle of Willis has been investigated by numerous scientists ever since. Classic form consists of two ICA's and their anastomotic connections with the vertebrobasilar system. It is vital for any neurosurgeon to become familiar with circle's variations as the classic type occurs only in 5-30\% of population (Klimek-Piotrowska W. et al., 2016) (J D Jones, 2020). Furthermore, any cerebral arterial variations such as fenestrations, duplications or persistent fetal arteries may play important role in various cerebrovascular diseases, in consequence they ought to be observed during brain surgeries (N. Stojanovic et al., 2009) (Dimmick SJ., 2009).

When two distinct vessels with different origins do not share one distal convergence the anomaly is then called arterial duplication (Lesley WS and Dalsania HJ., 2004) while vascular fenestrations are partial duplications within a vessel segment, which results in two distinct endothelium-lined channels that rejoin distally (Lesley WS, 2008) (Xiang Guo et al., 2018)

Fenestrations are rare, but well-known vascular variations of the cerebral arteries that more frequently occur in the anterior communicating artery, then in the vertebrobasilar system, the anterior cerebral artery, the middle cerebral artery, and the posterior cerebral artery (Horia Ples et al., 2015). Although they are mostly incidental, asymptomatic angiographic findings with reported incidence of 0,03 to $1 \%$ (Lotfi Hacein-Bey et al., 2002) they might precipitate vascular lesions such as AVM, aneurysmal dilatation or even ischemic symptoms. Their association with aneurysm formation is due to turbulent flow caused by defects of tunica media at both ends of fenestrated segments (Sanders WP et al., 1993) (Finlay HM, 1994). Increased hemodynamic stress precipitated by the anomaly along with the absent media are the main reasons of higher occurrence of aneurysms in patients with vascular fenestrations (Black SP, 1984).

\section{AIM OF THE STUDY}

Arterial fenestration is a developmental anomaly involving segmental splitting of the vessel. Although this type of cerebral vascular malformation is rare, it is often accompanied by other vascular abnormalities that pose a potential risk to patients, such as appearance of aneurysms. The aim of the study is to assess the frequency of occurrence and to 
determine the most frequent locations of cerebral vascular fenestration based on angio-CT scans performed in 2009-2018 at SPSK4 in Lublin.

\section{MATERIALS AND METHODS}

\section{Patients}

There were 6545 cranial angioTK examinations performed in SPSK4 in Lublin, Poland in the years 2009-2019. Cerebral vascular fenestration was found in 49 of them, which constituted $0.75 \%$. Angio-CT scans of patients with detected fenestration were re-analysed in order to confirm the described location of the malformation and to reveal or exclude the presence of an aneurysm.

In the studied group of patients with vascular fenestration, $75 \%(\mathrm{n}=37)$ were women, and $25 \%(\mathrm{n}=12)$ were men. The mean age of the patients at the time of the study was $51.08 \pm 19,07$ years (range 17-88 years) (Table 1). The mean age of women was 49,79.03 $\pm 18,26$ years and of men $55,17 \pm 21,72$ years (Table 2 ).

There was at least one cerebral aneurysm in 1,166 cases of all performed 6,545 angioCT scans, which is approximately $17.8 \%$ (Table 3 ). The existence of this type of vascular anomaly was diagnosed in 778 women (66.7\%) and 388 men $(33.3 \%)$ The mean age of women in this group was $57.48 \pm 13.71$, and men $56.32 \pm 14.335$ (Table 4).

Among 1,166 patients with aneurysm detected on imaging examination there were 328 who had multiple aneurysms, of which 233 (71.04\%) were women and 95 (28.96\%) were men (Table 4 and 5). The mean age of women with the presence of at least two aneurysms was $57.94 \pm 12.19$, and of men $57.15 \pm 14.17$ (Table 6).

\begin{tabular}{|c|c|c|c|c|c|c|}
\hline & $\mathrm{n}$ & $\mathrm{M}$ & $\mathrm{SD}$ & $\mathrm{Me}$ & $\mathrm{Q}_{1}-\mathrm{Q}_{3}$ & Min - Max \\
\hline Age & 49 & 51,08 & 19,07 & 55,00 & $33,00-65,00$ & $17,00-88,00$ \\
\hline
\end{tabular}

Table 1. Age of patients with vascular fenestration

\begin{tabular}{|c|c|c|c|c|c|c|c|}
\hline & Gender & $\mathrm{n}$ & $\mathrm{M}$ & $\mathrm{SD}$ & $\mathrm{Me}$ & $\mathrm{Q}_{1}-\mathrm{Q}_{3}$ & Min - Max \\
\hline Age & $\mathrm{F}$ & 37 & 49,76 & 18,26 & 54,00 & $33,00-63,00$ & $17,00-87,00$ \\
\hline Age & $\mathrm{M}$ & 12 & 55,17 & 21,72 & 60,50 & $36,50-68,00$ & $19,00-88,00$ \\
\hline
\end{tabular}


Table 2. Age of patients with vascular fenestration by gender

\begin{tabular}{|c|c|c|c|c|c|c|}
\hline & $\mathrm{n}$ & $\mathrm{M}$ & $\mathrm{SD}$ & $\mathrm{Me}$ & $\mathrm{Q}_{1}-\mathrm{Q}_{3}$ & Min - Max \\
\hline Age & 1166 & 57,09 & 13,93 & 58,00 & $49,00-67,00$ & $13,00-94,00$ \\
\hline
\end{tabular}

Table 3. Age of patients with brain aneurysm

\begin{tabular}{|c|c|c|c|c|c|c|c|}
\hline & Gender & $\mathrm{n}$ & $\mathrm{M}$ & $\mathrm{SD}$ & $\mathrm{Me}$ & $\mathrm{Q}_{1}-\mathrm{Q}_{3}$ & Min - Max \\
\hline Age & $\mathrm{F}$ & 778 & 57,48 & 13,71 & 58,00 & $49-67,00$ & $19,00-94,00$ \\
\hline Age & $\mathrm{M}$ & 388 & 56,32 & 14,35 & 58,00 & $48-66,00$ & $13,00-89,00$ \\
\hline
\end{tabular}

Table 4. Age of patients with brain aneurysm by gender

Table 5. Gender of

\begin{tabular}{|l|c|c|}
\hline & Number & Percent \\
\hline $\mathrm{W}$ & 233 & 71,04 \\
\hline $\mathrm{M}$ & 95 & 28,96 \\
\hline total & 328 & 100,00 \\
\hline
\end{tabular}

aneurysms

\begin{tabular}{|l|c|c|c|c|c|c|}
\hline Age & $\mathrm{n}$ & $\mathrm{M}$ & $\mathrm{SD}$ & $\mathrm{Me}$ & $\mathrm{Q}_{1}-\mathrm{Q}_{3}$ & Min - Max \\
\hline $\mathrm{W}$ & 233 & 57,94 & 12,19 & 59,00 & $50,00-66,50$ & $28,00-89,00$ \\
\hline $\mathrm{M}$ & 95 & 57,15 & 14,17 & 58,00 & $49,00-68,00$ & $14,00-89,00$ \\
\hline
\end{tabular}

Table 6. Age and gender of patients with multiple aneurysms

\section{CT and radiological findings}

Angio-CT studies were conducted using standard protocol used in the 1st Department of Radiology, Medical University of Lublin, using 64-row and 256-row scanners (General Electric Medical Systems): with scan range from the $\mathrm{C} 1$ to the vertex using tube voltage 120 $\mathrm{kVp}$, and automatic tube current modulation. SmartPrep tracking technique was used with 50 
$\mathrm{ml}$ of iodinated contrast agent followed by $40 \mathrm{ml}$ saline bolus, injected at $5 \mathrm{ml} / \mathrm{s}$. Contiguous sections were reconstructed with 0.5 -mm slice thickness.

Images were evaluated on a dedicated workstation (Advantage Workstation 4.3, GEMS) by radiologists with at least 6 years of experience in CTA studies. Analysis included assessment of axial scans, 3-mm and reformations: maximum intensity projections (MIP) and volume rendering (VR).

\section{Statistical analysis}

The normality of the distribution of quantitative variables was tested using the Shapiro-Wilk test. The value of the analyzed measurable variables was presented by means of the mean, standard deviation, median, lower and upper quartiles, as well as the minimum and maximum. Non-measurable parameters are presented numerically and as a percentage. The Kruskal-Wallis test was used to compare the age of the groups. In the case of qualitative variables, comparisons between individual features were made using the test of the existence of differences between two structure indices, while the chi2 test was used to test the relationship between these features. The level of significance was set at $p<0.05$, indicating the presence of statistically significant differences or assosiations. The database and statistical research were conducted by use of the STATISTICA 13.3 computer program (StatSoft, Poland).

\section{RESULTS}

\section{Incidence}

There were 6,545 cranial angio-CT examinations conducted at SPSK4 in 2009-2018 and the cerebral vessel fenestration was found in 49 of them, what constituted $0.75 \%$. One of the patients was diagnosed with two fenestrations, both on the same vessel (LICA). There were $29(75 \%)$ women and $12(25 \%)$ men in the described cases.

Table 7. shows the age of the patients in each type of fenestration. The patient's lowest age was for ICA fenestration $(\mathrm{Me}=17.00)$, and the highest was for MCA $(\mathrm{Me}=$ 70.00). Median patient age for the most common fenestrations: ACA was 60 years, BA was 46 years, and AComA was 63 years. Statistical analysis did not reveal significant differences in the age of patients in the groups of individual vascular fenestration $(\mathrm{p}>0.05)$. 


\begin{tabular}{|r|r|r|r|r|}
\hline Vessel & $\mathrm{n}$ & $\mathrm{M}$ & $\mathrm{SD}$ & $\mathrm{M}$ \\
\hline ACA & 15 & 54,60 & 16,37 & 60,00 \\
\hline VA & 4 & 41,50 & 16,54 & 45,00 \\
\hline BA & 15 & 47,73 & 19,48 & 46,00 \\
\hline MCA & 1 & 70,00 & & 70,00 \\
\hline Acom & 11 & 56,64 & 22,21 & 63,00 \\
\hline PCA & 2 & 46,00 & 2,83 & 46,00 \\
\hline ICA & 1 & 17,00 & & 17,00 \\
\hline & \multicolumn{2}{|c|}{ Statistical analysis $: \mathrm{H}=7,552 ; \mathrm{p}=0,273$} \\
\hline
\end{tabular}

Table 7. Patient age by type of fenestration in vessels

Table 8 depicts the gender of the patients in the different groups of cerebrovascular fenestrations. It was shown that the occurrence of different types of fenestration was similar in the group of women and men, except for VA, as this type was slightly more common in group of men $(16,67 \%)$ than in women $(5,41 \%)$. However, these differences were not statistically significant $(\mathrm{P}=0.216)$.

\begin{tabular}{|l|l|l|l|l|l|l|l|l|}
\hline & gender & $\mathrm{n}$ & $\%$ & & gender & $\mathrm{n}$ & $\%$ & $\mathrm{p}$ \\
\hline ACA & $\mathrm{F}$ & 12 & 32,43 & & $\mathrm{M}$ & 3 & 25,00 & 0,626 \\
\hline VA & $\mathrm{F}$ & 2 & 5,41 & & $\mathrm{M}$ & 2 & 16,67 & 0,216 \\
\hline BA & $\mathrm{F}$ & 12 & 32,43 & & $\mathrm{M}$ & 3 & 25,00 & 0,628 \\
\hline MCA & $\mathrm{F}$ & 1 & 2,70 & & $\mathrm{M}$ & 0 & 0,00 & \\
\hline Acom & F & 8 & 21,62 & & $\mathrm{M}$ & 3 & 25,00 & 0,807 \\
\hline PCA & F & 1 & 2,70 & & M & 1 & 8,33 & 0,392 \\
\hline ICA & F & 1 & 2,70 & & M & 0 & 0,00 & \\
\hline
\end{tabular}

Table 8 . Gender of patients by type of vascular fenestration $(n=49)$

The study shows that from among 1,166 patients diagnosed with at least one cerebral aneurysm, $66.72 \%$ were women (778 people) and $33.28 \%$ were men (Table 9.).

The number of patients, in whom multiple aneurysms were detected in the head angioCT study, was 328. Among them as many as 71.04\% (233) were female and the remaining 
$28.96 \%(95)$ were male. The mean age of the patients was similar in both the female and male groups and it was approximately 57 years (57.94 females; 57.15 males). The youngest representative of this group was a 14-years old and the oldest one was 89 years old. The majority of patients with multiple aneurysms had two aneurysms (228 people), three aneurysms occurred in 70 people and four in 21 patients. Five or six aneurysms occurred in a total of 9 patients. The group of patients with multiple aneurysms accounted for $28.13 \%$ of all 1,166 patients diagnosed with this type of vascular anomaly.

\begin{tabular}{|l|c|c|}
\hline & $\mathrm{n}$ & $\%$ \\
\hline $\mathrm{F}$ & 778 & 66,72 \\
\hline $\mathrm{M}$ & 388 & 33,28 \\
\hline total & 1166 & 100,00 \\
\hline
\end{tabular}

Table 9. Occurrence of aneurysms by gender

\section{Localization}

The study showed that the most common vascular fenestrations were those located in ACA (30.61\%) (Pic. 1), BA (30.61\%) (Pic. 2) and AComA (22.45\%) (Pic 3 and 4), while other fenestrations occured infrequently (Table 10)(Pic. 5 and 6). There was only 1 patient of all the 6,645 angio-CT examined who had more than one fenestration - 2 ACA fenestrations.

\begin{tabular}{|l|l|}
\hline vessel & $\mathrm{n}(\%)$ \\
\hline ACA & $16(32,00)$ \\
\hline VA & $4(8,00)$ \\
\hline BA & $15(30,00)$ \\
\hline MCA & $1(2,00)$ \\
\hline Acom & $11(22,00)$ \\
\hline PCA & $2(4,00)$ \\
\hline ICA & $1(2,00)$ \\
\hline total & $\mathbf{5 0 ( 1 0 0 , 0 0 )}$ \\
\hline
\end{tabular}


Table 10. Incidence of fenestration by arteries. In one case, patient possessed two fenestrations, both on ACA.

The group of patients with aneurysm on imaging examination comprised 1166 people. A total of 1630 aneurysms were found in them, most of which were located in MCA - 629 (38.59\%), ICA - 466 (28.59\%) and ACom - 192 (11.78\%)(Table 11.). There were 328 patients of the 1,166 who had multiple aneurysms thus they constituted $28,13 \%$ of the group.

\begin{tabular}{|c|c|}
\hline Artery & $\mathbf{n}(\mathbf{\%})$ \\
\hline ICA & $466(28,59)$ \\
\hline MCA & $629(38,59)$ \\
\hline Acom & $192(11,78)$ \\
\hline ACA & $29(1,78)$ \\
\hline Peri & $35(2,15)$ \\
\hline VA & $124(7,61)$ \\
\hline BA & $2(0,12)$ \\
\hline PICA & $27(1,66)$ \\
\hline PCA & $13(0,80)$ \\
\hline Pcom & $1(0,06)$ \\
\hline ChorA & $1(0,06)$ \\
\hline RCA & $1(0,06)$ \\
\hline PeriCall & $1(0,06)$ \\
\hline Meningeal & $1(0,06)$ \\
\hline Frontobasalis & $2(0,12)$ \\
\hline Opht & $1(0,06)$ \\
\hline Callmarg & $\mathbf{1 6 3 0}(\mathbf{1 0 0 , 0 0 )}$ \\
\hline Total & $1 n c i d e n c e f a n c u r y s$ \\
\hline
\end{tabular}

Table 11. Incidence of aneurysms by arteries 


\section{Association with brain aneurysms}

In the group of 49 examined patients with cerebral fenestration based on cranial angio-CT scans, 11 (23.91\%) had intracranial aneurysms, and 38 (76.09\%) had no such anomalies.

However, rate of occurrence of both vascular malformations (fenestration and aneurysm) is accounted for $0,17 \%$ of all angio-CT scans (6545) performed in 2009-2019 at SPSK4 in Lublin. During the study there were also checked involved arteries and there was not found relevant influence of fenestration on the occurrence of a particular aneurysm. In more than $50 \%$ of the cases of coexistence, anterior cerebral artery aneurysm was involved with a fenestration located on various vessels (Table 14).

Aneurysms alone, with no other vascular malformation were diagnosed in $17,65 \%$ of all the examined individuals what involved 1155 patients. Nevertheless, some of the patients were more prone to vascular malformations than others, which is clearly depicted in table 12 . There were 328 individuals diagnosed with multiple aneurysms what accounts for $28,13 \%$. Out of all the patients with aneurysm $9 \%$ had more than 2 aneurysms and just one having six (Table 13). Among patients with multiple aneurysms, just two of them also had an arterial fenestration.

\begin{tabular}{|c|c|}
\hline & $\mathrm{n}(\%)$ \\
\hline no malformations & $5341(81,60)$ \\
\hline aneurysm alone & $1155(17,65)$ \\
\hline fenestration alone & $38(0,58)$ \\
\hline both malformations & $11(0,17)$ \\
\hline total & 6545 \\
\hline
\end{tabular}

Table 12. Occurrence of vascular malformations in examined group of patients

\begin{tabular}{|c|c|c|c|}
\hline $\begin{array}{c}\text { Number of } \\
\text { aneurysms }\end{array}$ & $\mathrm{n}$ & $\%$ & Percent \% \\
\hline 1 & 838 & 71,87 & 71,91 \\
\hline 2 & 228 & 19,55 & \\
\hline 3 & 70 & 6,00 & \\
\hline
\end{tabular}




\begin{tabular}{|c|c|c|c|}
\hline $\begin{array}{c}\text { Number of } \\
\text { aneurysms }\end{array}$ & $\mathrm{n}$ & $\%$ & Percent \% \\
\hline 4 & 21 & 1,80 & 28,13 \\
\hline 5 & 1 & 0,69 & \\
\hline 6 & 1166 & 0,09 & \\
\hline Total & 8 & 100,00 & 100,00 \\
\hline
\end{tabular}

Table 13. Percentage of patients with multiple aneurysms.

\begin{tabular}{|c|c|c|}
\hline & $\mathrm{n}$ & $\%$ \\
\hline ACA & 6 & 54,55 \\
\hline VA & 1 & 9,09 \\
\hline BA & 2 & 18,18 \\
\hline MCA & 1 & 9,09 \\
\hline Acom & 1 & 9,09 \\
\hline
\end{tabular}

Table 14. Occurrence of aneurysms in patients with various types of vascular fenestration

\begin{tabular}{|c|c|c|c|}
\hline \multirow{2}{*}{ Aneurysm } & \multicolumn{2}{|c|}{ Fenestration } & \multirow{2}{*}{ Total } \\
\cline { 2 - 3 } & no & yes & \\
\hline No & $5341,(99,29)$ & $38,(0,71)$ & $5379,(100,00)$ \\
\hline Single aneurysm & $829,(98,93)$ & $9,(1,07)$ & $838(100,00)$ \\
\hline $\begin{array}{c}\text { Multiple } \\
\text { aneurysms }\end{array}$ & $326,(99,39)$ & $2,(0,61)$ & $328(100,00)$ \\
\hline
\end{tabular}

Table 15. Coexistence of fenestrations with single and multiple aneurysms. The percentage of fenestration was compared to the subgroups of single aneurysm and multiple aneurysm: with $p=0.464$ there are no statistically significant differences in the incidence of fenestration between the subgroup of patients with single aneurysm and the subgroup with multiple aneurysms.

\section{DISCUSSION}

\section{Incidence}

The results regarding the occurrence of cerebral vascular fenestration vary considerably among different studies. Moreover, it seems that results are largely influenced by the type of study conducted. There were 6,545 angio-CT scans performed in SPSK4 and fenestrations were found in 49 patients, which contitutes $0.75 \%$, that is less than reported in other CT (3.5-12.9\%), MR (2.8-3.0\%) and DSA (22.9-28\%), and significantly less than that 
indicated by post-mortem studies (Daniel L Cooke et al, 2014) (L.A. Arraez-Aybar et al, 2012) (Bayrak Aylin Hasanefendioglu et al, 2011) (Zhen-Kui Sun et al, 2012) (Akira Uchino et al, 2011) (S.B.T. van Rooij et al., 2009).

The above percentage discrepancies are due to the different sensitivity of each of these methods. Small vascular malformations may be difficult to notice on CT as well as MRI, but they can be effectively visualized in DSA using 3D reconstruction (Bożek Paweł et al, 2012). The median age of examined patients for the most common fenestrations was 55 years for ACA, 48 years for BA and 57 years for ACom, which confirms the results obtained in other scientific studies, indicating a more frequent presence of vascular fenestration in the elderly (van Rooij et al., 2015).

However, taking into consideration the fact, that imaging studies of the head are more often performed on older people than on younger ones, it can be concluded that the detectability of vascular fenestration is greater in the elderly than their presence. It should also be added that the significant proportion of vascular malformations is found accidentally or at the time of a problem with another related vascular anomaly, e.g. in the event of an aneurysm rupture.

The study shows that of all 6,545 patients who underwent angio-CT of the head in years 2009-2019, 1,166 suffered from aneurysm. This constitutes $17.8 \%$ of the examined patients, which is far more than it was estimated in the general population- 2-6\% (Pavlos Texakalidis, 2019) (D. Krex, 2006). In retrospective angiographic studies, the incidence of aneurysms was approximately $3.7 \%$, and in prospective angiographic studies it was $6 \%$. (G J Rinkiel, 1998). This kind of discrepancy in the results may be caused by the fact that patients, whose angio-CT scans have been described in this study and taken into account in calculating the statistical data, were conducted due to occurrence of indications for this type of imaging, e.g. symptoms indicating a ruptured aneurysm of the cerebral vessels.

\section{Localization}

The most common part of the circle of Willis, in which fenestration is reported, is the anterior part of the circle constituted by ACA and ACom, being found in 7-40\% in autopsy, in $6.9 \%$ in angioCT and up to $20.7 \%$ in 3D DSA.(Pic.3) (Pic.4) Subsequently BA makes - 1-6\% in autopsy, 2.4\% in CTA, whereas DSA constitutes 2\% (Pic.2). (Bożek Paweł et al, 2012) (Okahara Mika et al, 2002) (Bharatha Aditya et al, 2008) (H El Otmani, 2020). 
This research also shows that fenestrations most often occur in the anterior part of the arterial circle of the brain - ACA (30,61\%), ACom (22,45\%) and within BA (30.61\%) and they are rarely described in other blood vessels.

Fenestration is not the only common vascular anomaly in ACom. Its complex anatomy can take the form of standard fenestration, duplication, or a tangle-like appearance in over 40$60 \%$ of cases (Serizawa T. et al, 1997) (Gomes F. B. et al, 1986) (Bayrak Aylin Hasanefendioglu et al, 2011).

Knowledge of the most common locations of cerebral vascular fenestration may prove essential in practicing as an neurosurgeon or an interventional radiologist.

The most common locations of intracranial aneurysms are the anterior communicating artery $(35 \%)$, the internal carotid artery (30\%), the middle cerebral artery $(22 \%)$, and the basilar artery. (Alexander Keedy, 2006) (Junhui Chen, 2020) (B Zhao, 2019). The arteries, that were visualized during the study with angio-CT, are also most frequently found in the above-mentioned vessels. MCA (38.59\%) were first, followed by ICA (28.59\%) and ACom $(11.78 \%)$. Among the vessels of the posterior Willis circle, such vascular lesions were most often found on BA (7.61\%).

\section{Associated vascular diseases}

There have been published many case reports of patients with concomitant cerebral vascular fenestration and aneurysms until now, although the mutual dependence of these vascular anomalies has not been clearly established. During the research, a number of studies describing the simultaneous presence of vascular fenestration and other disorders such as arteriovenous malformations (Uchino A. et al, 2001) or cerebral aneurysms was analysed (de Gast AN, 2008) (Fujimoto K, 2007) (Gruber TJ, 2010) (Islak C, 2002) (Tasker AD, 1997). There were few articles that mentioned about coexistence of fenestration with multiple aneurysms (Saatci I, 2002) (M. Polguj, 2013). Scientific studies have shown similiarity in the structure of the middle layer of the vessel wall within the proximal and distal fragments of the fenestration and the branches of the cerebral arteries, in the form of focal defects, that is most likely due to a response to the hemodynamic forces acting on them. These types of defects predispose to the formation of aneurysms (Finlay HM, 1994) (Bharatha Aditya et al, 2008).

In this study, intracranial aneurysms were diagnosed in 11 out of 49 patients with vascular fenestration $(22.45 \%)$, and in 38 such anomaly was not found (77.45\%). There were angio-CT scans performed in years 2009-2018 on patients highly suspected of cerebral 
aneurysms, these malformations were described in $17.81 \%$ and they coexisted with arterial fenestration in $0,94 \%$. Some studies show the prevalence of intracranial aneurysms in adults in the range of $2-2.7 \%$ (King Jr J.T., 1997) (Steiner T. et al, 2013). There are studies that show their more frequent occurrence due to coexisting diseases that required appropriate diagnostics, that contributed to an increase of the detection of aneurysms (Horikoshi T. et al, 2002) (Sugai Y. et al, 1994).

Among the 11 cases of coexisting malformation that were described in the study, most number of fenestrations were found in the area of ACA (6) and BA (3) while the largest number of aneurysms were found on MCA (4) and ICA (2) i.e. fragments of the arterial circle of the brain where both malformations are most often detected (Bożek Paweł et al, 2012). Nevertheless, many case reports show frequent occurrence of aneurysms associated with fenestration of the proximal basilar artery (35.5\%) (Campos J. et al, 1987). This study discovered no such correlation (Table 14).

The aim of the study was to determine whether detection of an arterial fenestrations increase the possibility of finding cerebral aneurysms. Observations made during the study lead to the conclusion that occurrence of aneurysms is highly greater in population with fenestration - $22,44 \%$ comparing to general population, that extends from $2 \%$ to $6 \%$ according to various sources of information. The conclusion of this study should be extrapolated to clinical field because of the fact, that patients with diagnosed fenestration should be controlled more often in comparison to general population due to the increased risk of occurrence of aneurysm.

The research was also focused on examining a connection between existence of multiple aneurysms with fenestrations, but in the analysed group of patients the correlation was not statistically significant (Table 15).

\section{CONFLICT OF INTEREST}

On behalf of all authors, the corresponding author states that there is no conflict of interest.

\section{LEGAL STATEMENTS}

All methods were carried out in accordance with relevant guidelines and regulations.

All experimental protocols were approved by Bioetic Comission of Medical University of Lublin, Poland 
Informed consent was obtained from all subjects and/or their legal guardian(s) for those who are less than 16 years old of age.

\section{CONCLUSIONS}

The study, that was based on 6545 angio-CT scans of the head, determined the incidence of cerebrovascular fenestration, which was $0.70 \%$ of which $63 \%$ were women and $37 \%$ were men. The described vascular anomalies most often occurred in the anterior part of the Willis circle - ACA (32.61\%) (Pic. 1), ACom (23.91\%), and also in BA (30.43\%). It was shown that the occurrence of different types of fenestrations was similar in the group of women and men. Among the patients with described fenestrations, 11 had intracranial aneurysms (23.91\%). Patients with vascular fenestrations are at higher risk of developing other vascular malformations. Also, having multiple aneurysms does not correlate with more frequent occurrence of vascular fenestration comparing to patients with one aneurysm. 
FENESTRATIONS IN ANGIO-CT

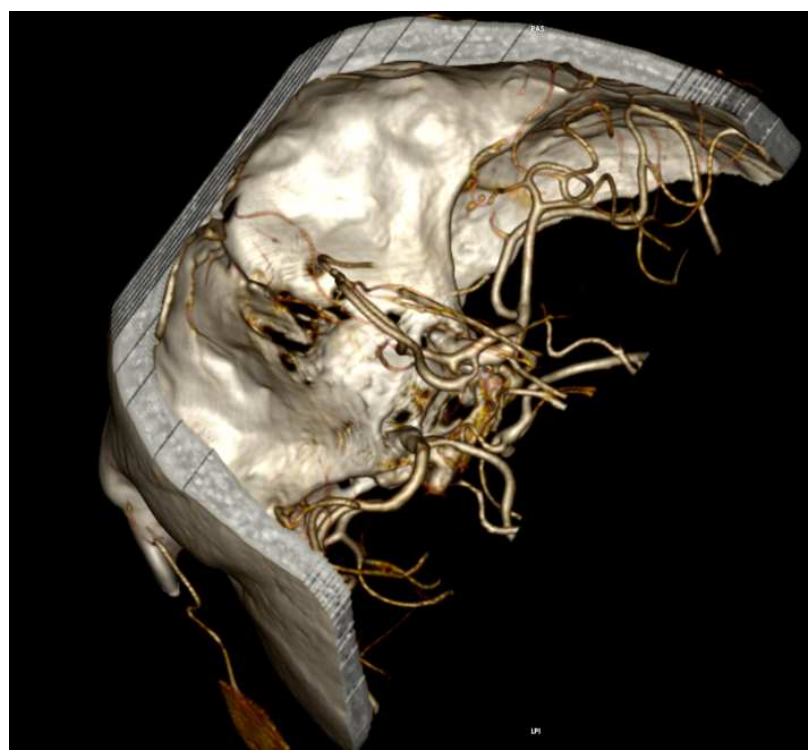

Pic. 3. AcomA fenestration - vascular 3D reconstruction

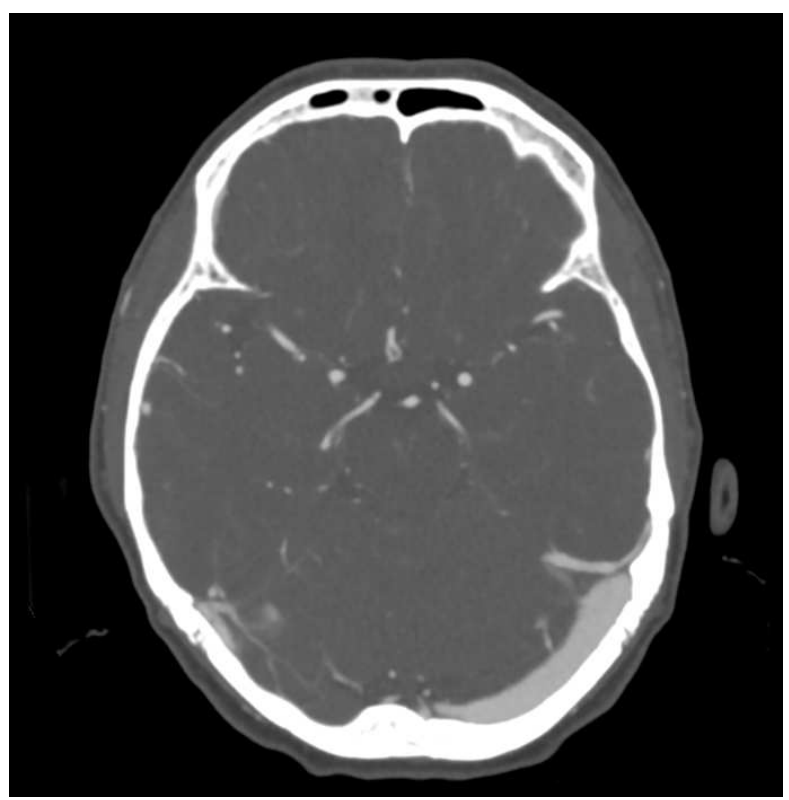

Pic. 4. AcomA fenestration in angio-CT

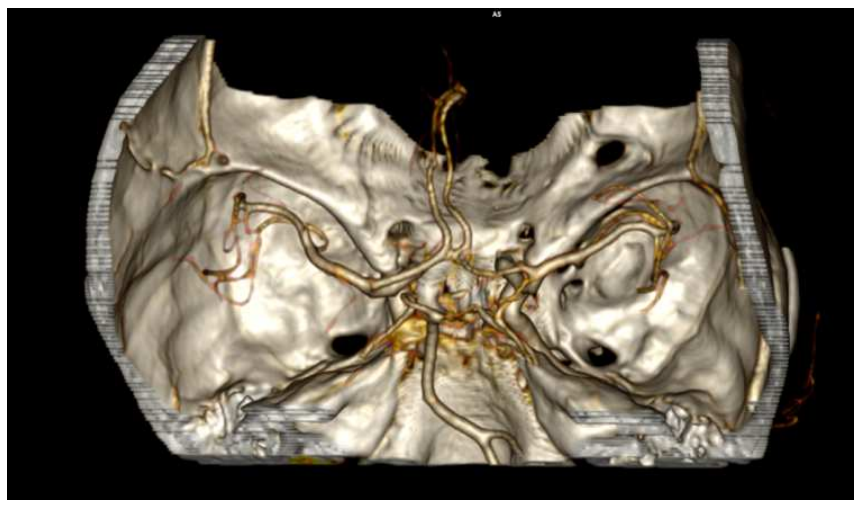

Pic. 1. RACA fenestration in vascular 3D reconstruction 


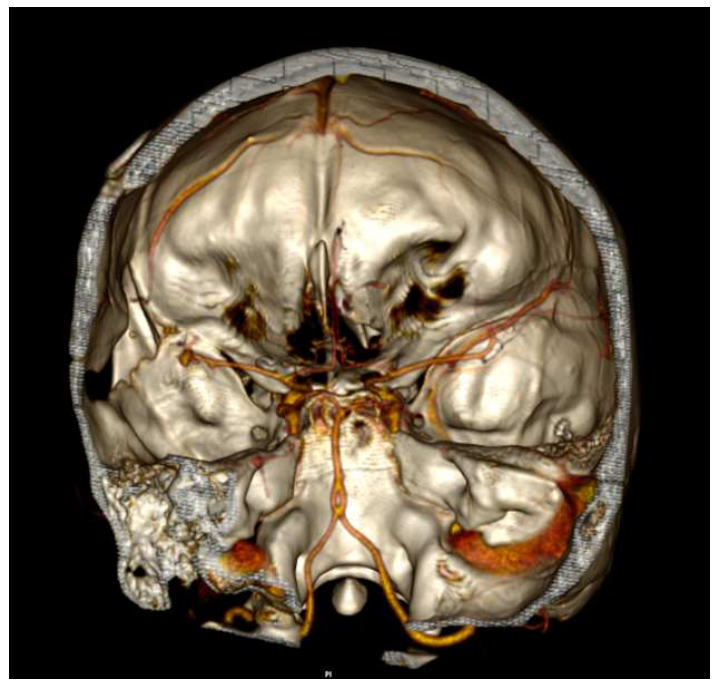

Pic. 2. BA fenestration in vascular 3D reconstruction

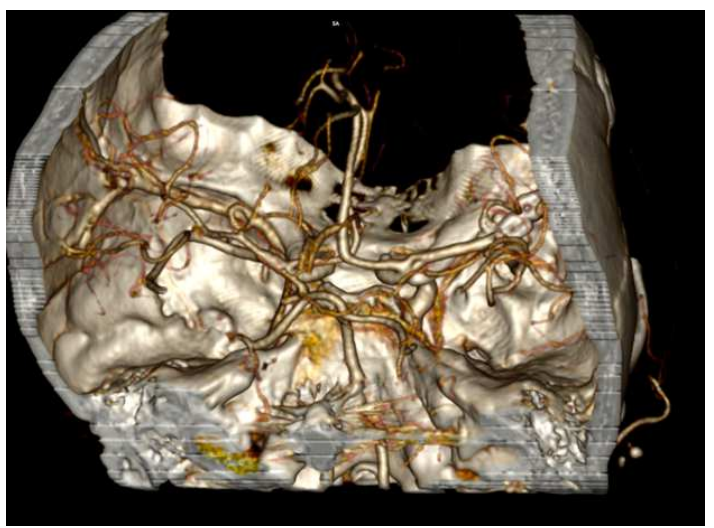

Pic. 5. RMCA fenestration in vascular 3D reconstruction

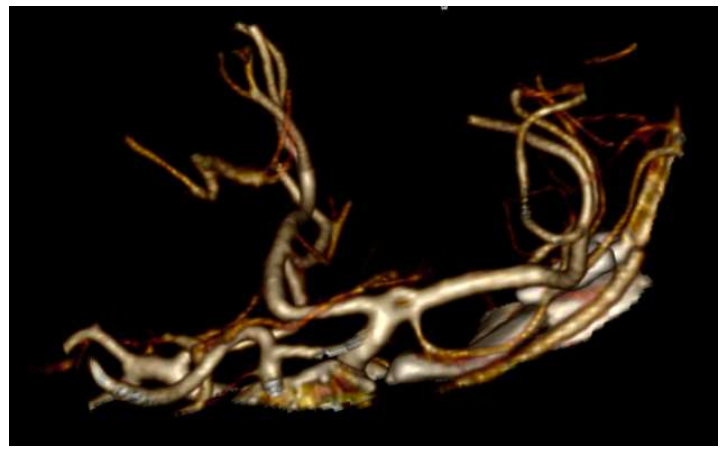

Pic. 6. LMCA fenestration in vascular 3D reconstruction 


\section{BIBLIOGRAPHY}

A. Meyer R. Hierons, Observations of the history of the "Circle of Willis" [Article] // Med Hist.. - Apr 1962. - pp. 119-130.

Akira Uchino et al Fenestrations of the intracranial vertebrobasilar system diagnosed by MR angiography [Article] // Neuroradiology. - Jul 2011. - pp. 445-450.

Alexander Keedy An overview of intracranial aneurysms [Article] // Mcgill J Med.. - Jul 2006. - pp. 141-146.

B Zhao H Xing, L Fan et al Endovascular Coiling versus Surgical Clipping of Very Small Ruptured Anterior Communicating Artery Aneurysms [Article] // World Neurosurg. - 2019.

Bayrak Aylin Hasanefendioglu et al The frequency of intracranial arterial fenestrations: A study with 64-detector CT-angiography [Article] // European Journal of Radiology. - Mar 2011. - pp. 392-396.

Bharatha Aditya et al Intracranial arterial fenestrations: frequency on CT angiography and association with other vascular lesions [Article] // Surgical and Radiologic Anatomy. - Mar 2008. - pp. 397-401.

Black SP Ansbacher LE, Saccular aneurysm associated with segmental duplication of the basilar artery. A morphological study. [Article] // J Neurosurgery. - Dec 1984. - pp. 10051008.

Bożek Pawel et al Detection of cerebral artery fenestrations by computer tomography angiography [Article] // Neurologia i Neurochirurgia Polska. - 2012. - pp. 239-244.

Campos J. et al Saccular aneurysms in basilar artery fenetration [Article] // AJNR Am J Neuroradiol.. - Mar-Apr 1987. - pp. 233-6.

D. Krex S. Fortun, E. Kuhlish et al. The role of endothelial nitric oxide synthase (eNOS) genetic variants in European patients with intracranial aneurysms [Article] // J. Cereb. Blood Flow Metab.. - 2006. - pp. 1250-1255.

Daniel L Cooke et al Cerebral Arterial Fenestrations [Article] // Interv Neuroradiol. - Jun 2014. - pp. 261-274.

de Gast AN van Rooij WJ, Sluzewski M. Fenestrations of the anterior communicating artery: incidence on 3D angiography and relationship to aneurysms [Article] // Am J Neuroradiol. - 2008. - pp. 296-298.

Dimmick SJ. Normal variants of the cerebral circulation at multidetector CT angiography. [Article] // Radiographics. - Jul-Aug 2009. - pp. 1023-1043.

Feindel W. Willi's Cerebri Anatome [Article] // J R Soc Med.. - Jul 2003. - p. 368.

Finlay HM Canham PB, The layered fabric of cerebral artery fenestrations. [Article] //

Stroke. - Sep 1994. - pp. 1799-1806.

Fujimoto K Kawai S, Yonezawa T, Masui K, Nishi N, Maekawa M, Uranishi R Basilar trunk aneurysms with associated fenestration treated by using Guglielmi detachable coils: two cases reports. [Article] // J Stroke Cerebrovasc Dis. - 2007. - pp. 84-87.

G J Rinkiel et al., Prevalence and risk of rupture of intracranial aneurysms: a systematic review [Article] // Stroke. - Jan 1998. - pp. 251-6.

Gomes F. B. et al Microanatomy of the anterior cerebral artery [Article] // Surgical Neurology. - Aug 1986. - pp. 129-141.

Gruber TJ Ogilvy CS, Hauck EF, Levy EI, Hopkins LN, Siddiqui AH Endovascular treatment of a large aneurysm arising from a basilar trunk fenestration using the waffle-cone technique. [Article] // Neurosurgery. - 2010.

H El Otmani V Fotso, B El Moutawakil, M A Rafai Basilar artery fenestration and ischemic stroke: An unclear causal relationship [Article] // J Med Vasc. - 2020.

Horia Ples et al. Fenestration of the middle cerebral artery in a patient who presented with transient ischemic [Article] // Rom J Morphol Embryol. - 2015. - pp. 861-865. 
Horikoshi T. et al Retrospective Analysis of the Prevalence of Asymptomatic Cerebral Aneurysm in 4518 Undergoing Magnetic Resonance Angiography - When Does Cerebral Aneurysm Develop? - [Article] // Neurol Med Chir. - Mar 2002. - pp. 105-12.

Islak C Kocer N, Kantarci F, Saatci I, Uzma O, Canbaz B Endovascular management of basilar artery aneurysms associated with fenestrations. [Article] // AJNR Am J Neuroradiol. 2002.

J D Jones P. Castanho, P. Bazira, K. Sanders Anatomical variations of the circle of Willis and their prevalence, with a focus on the posterior communicating artery: A literature review and meta-analysis [Article] // Clin Anat. - 2020.

Junhui Chen Mingchang Li, Xun Zhu et al. Anterior Communicating Artery Aneurysms: Anatomical Considerations and Microsurgical Strategies [Article] // Front Neurol. - 2020.

King Jr J.T. Epidmiology of aneurysmal subarachnoid hemorrage [Article] // Neuroimaging Clin N Am.. - Nov 1997. - p. 65968.

Klimek-Piotrowska W. et al. A multitude of variations in the configuration of the circle of Willis: an autopsy study. [Article] // Anat Sci Int.. - Sept 2016. - pp. 325-333.

L.A. Arraez-Aybar et al Prevalence of fenestrated basilar artery with magnetic resonance angiography: a transversal study [Article] // Surgical and Radiologic Anatomy. - Dec 2012. pp. 487-493.

Lesley WS and Dalsania HJ. Double origin of the posterior inferior cerebellar artery.

[Article] // AJNR Am J Neuroradiol.. - Mar 2004. - pp. 425-457.

Lesley WS Fenestration of the posterior inferior cerebellar artery [Article] // The Cerebellum. - Apr 2008. - pp. 240-241.

Lotfi Hacein-Bey et al. Saccular Aneurysm Associated with Posterior Cerebral Artery Fenestration Manifesting as a Subarachnoid Hemorrhage in a Child [Article] // AJNR Am J Neuroradiol. - Sep 2002. - pp. 1291-1294.

M. Polguj M. Majos, M. Topol, A. Majos An asymmetrical fenestration of the basilar artery coexisting with two aneurysms in a patient with subarachnoid haemorrhage: case report and review of the literature [Article] // Folia morph.. - 2013.

N. Stojanovic et al. Presence of anatomical variations of the circle of Willis in patients undergoing surgical treatment for ruptured intracranial aneurysms [Article] // Vojnosanit Pregl . - 2009. - pp. 711-717.

Okahara Mika et al Anatomic variations of the cerebral arteries and their embryology: a pictorial review [Article] // Eur Radiol.. - Oct 2002.

Pavlos Texakalidis et al., Aneurysm Formation, Growth, and Rupture: The Biology and Physics of Cerebral Aneurysms [Article] // World Neurosurg.. - Oct 2019. - pp. 277-284.

S.B.T. van Rooij et al. Fenestrations of Intracranial Arteries Detected with 3D Rotational Angiography [Article] // AJNR Am J Neuroradiol. - Aug 2009. - pp. 1347-1350.

Saatci I Cekirge HS, Karcaaltincaba M, et al. Endovascular treatment of kissing aneurysms at the fenestrated basilar artery: case report with literature review. [Article] // Surg Neurol . 2002. - pp. 54-58.

Sanders WP et al. Fenestration of intracranial arteries with special attention to associated aneurysms and other anomalies [Article] // AJNR Am J Neuroradiol.. - May-Jun 1993. - pp. 675-680.

Serizawa T. et al Microsurgical anatomy and clinical significance of the anterior communicating artery and its perforating branches [Article] // Neurosurgery. - Jun 1997. - pp. 1211-1218.

Steiner T. et al European Stroke Organization guidelines for the management of intracranial aneurysms and subarachnoid haemorrhage [Article] // Cerebrovasc Dis.. - 2013. - pp. 93-112. Sugai Y. et al Angiographical frequency of unruptured incidental intracranial aneurysms [Article] // No Shinkei Geka.. - May 1994. - pp. 429-32. 
Tasker AD Byrne JV Basilar artery fenestration in association with aneurysms of the posterior cerebral circulation. [Article]. - [s.1.] : Neuroradiology, 1997.

Uchino A. et al Association of cerebral arteriovenous malformation with cerebral arterial fenestration [Article] // Eur Radiol.. - 2001. - pp. 493-6.

van Rooij et al. Fenestrations of Intracranial Arteries [Article] // AJNR. - Jun 2015. - pp. 1167-1170.

Xiang Guo et al. Intracranial Arterial Fenestration and Risk of Aneurysm: A Systematic Review and Meta-Analysis [Article] // World Neurosurgery. - Apr 2018.

Zhen-Kui Sun et al Fenestrations accompanied by intracranial aneurysms assessed with magnetic resonance angiography [Article] // Neurology India. - Mar 2012. - pp. 45-49. 